\title{
THREE-DIMENSIONAL DATA MODELLING FOR UNDERGROUND UTILITY NETWORK MAPPING
}

\author{
Jingya YAN ${ }^{1 *}$, Siow Wei JAW ${ }^{1,2,3}$, Rob Van Son $^{1}$, Kean Huat SOON ${ }^{4}$, Gerhard SCHROTTER ${ }^{5}$ \\ ${ }^{1}$ ETH Zurich, Future Cities Laboratory, Singapore-ETH Centre - (Jingya.yan, vanson)@ arch.ethz.ch \\ ${ }^{2}$ Geoscience \& Digital Eaeth Centre (INSTeG), Research Institute for Sustainable Environment, \\ Universiti Teknologi Malaysia, Malaysia - swjaw@utm.my \\ ${ }^{3}$ Department of Geoinformation, Faculty of Built Environment and Surveying, Universiti Teknologi Malaysia, Malaysia \\ ${ }^{4}$ Singapore Land Authority, Singapore SOON_Kean_Huat@sla.gov.sg \\ ${ }^{5}$ Geomatik + Vermessung Stadt Zurich, Zurich, Switzerland Gerhard.Schrotter@zuerich.ch
}

\section{Commission IV, WG IV/5}

KEY WORDS: 3D Data Modelling, Underground Utility Networks, Underground space planning, Underground mapping, Utility cadastre

\begin{abstract}
:
Cities around the world face an increasing need for land as density in urban areas increases rapidly. The pressure to expand a city's space is especially acute for a city-state like Singapore. How to make better use of underground space? This issue becomes much more emergent in the urban development. In the big data era, a data-driven approach of underground spaces is necessary for the sustainable development of a city along with rapid urbanization. A reliable three dimensional (3D) digital map of utility networks is crucial for urban planners to understand one of the most impactful aspects of the underground space planning. The mapping underground utility networks is a challenging task, especially for cities with limited land resources, congested underground spaces, and a lack of uniform existing practices. This paper proposes a framework to organise the workflow from an underground utility data survey to data use. This framework includes two core parts: A 3D utility network data model that aims to convert utility survey data to 3D geospatial information, and a 3D utility cadastral data model that supports utility ownership management. It is expected that reliable and accurate information on underground utility networks can lead to a better understanding and management of underground space, which eventually contributes to better city planning, making the unseen structures visible.
\end{abstract}

\section{INTRODUCTION}

\subsection{Motivation}

In a land-scarce city such as Singapore, urban planners are facing challenges to optimize urban land usage. Rapid urbanization of densely populated cities has caused available above ground land to be limited. Underground spaces offer enormous potential. To achieve this potential and support well-informed planning decisions, a good understanding of what exists underground - especially that which is concealed - is necessary. This has fostered the need for holistic, data-driven planning of underground spaces for the sustainable development of a city along with rapid urbanization (Jaw et al., 2018). Currently, some of the places around the world have interests to develop the 3D mapping of underground utility network and utility cadastral management. For instance, Switzerland began to develop a national utility cadastre since 2009, and the Canton of Zurich has established a comprehensive Canton-wide utility cadastre system (Figure 1) under the utility cadastre regulation since 2012. Additionally, the United States of America, United Kingdom, Malaysia, Canada and some others have developed a 3D map of underground utility networks (Pouliot and Girard, 2016, Tan and Looi, 2013).

To make better use of underground space, Singapore needs the reliable and accurate information of underground utilities. Figure 2 shows an example of currently available utility data in Singapore. This data is available only in two dimensional (2D) formats,

\footnotetext{
${ }^{*}$ Corresponding author
}

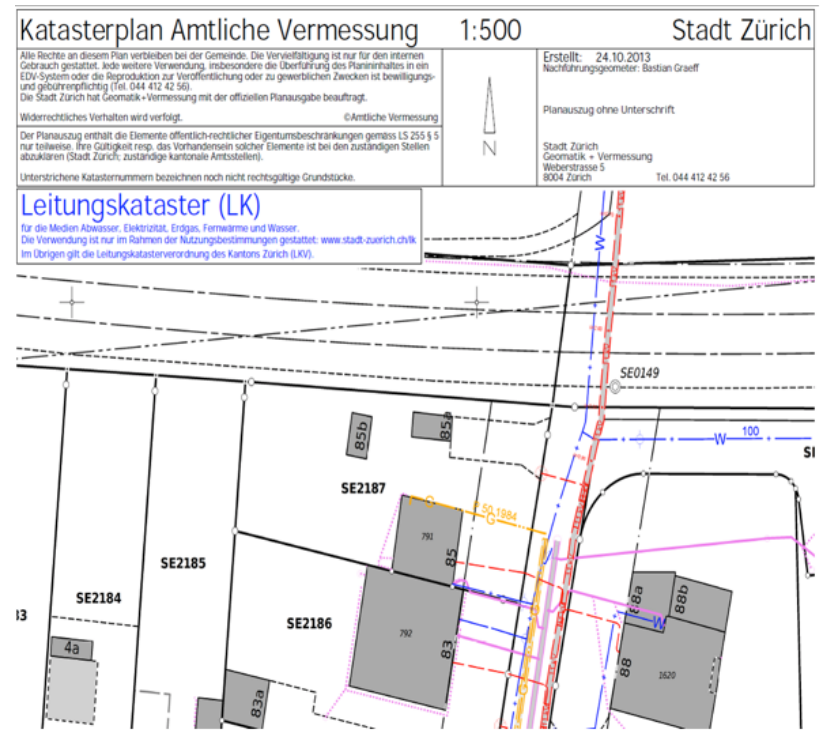

Figure 1. Example of print out of utility cadaster (Source: Leitungskataster, Stadt Zurich, 2017).

and lacks detailed and usable information about its as-built depth and location, causing a mismatch with the existing above ground 3D information and supporting systems. The data represents asdesigned and not as-built information, not taking into account any deviations that may have occurred during construction. There- 


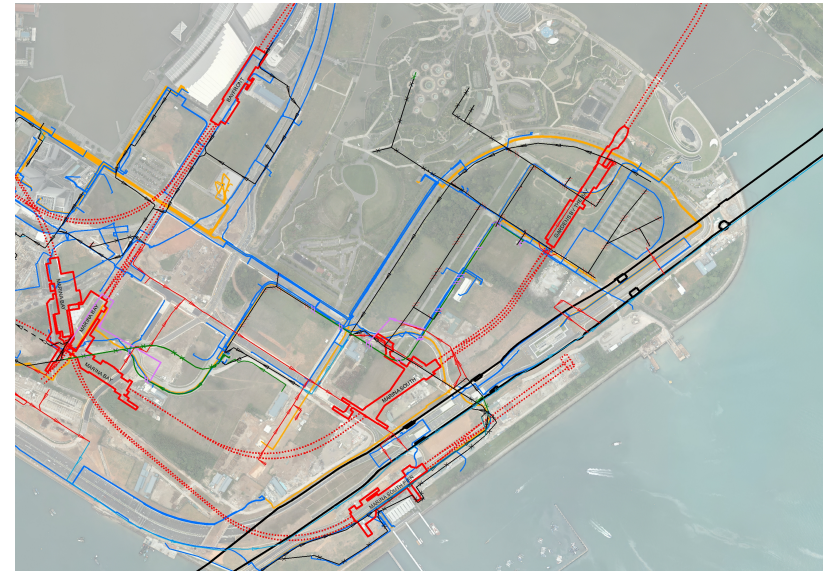

Figure 2. An example of utility data in Singapore (Source: Singapore Land Authority, 2018).

fore, over the past years, the Singapore government has engaged in enhancing underground utility mapping accuracy and reducing the cost of underground development. To further this effort, the Singapore Land Authority (SLA) announced the release of the first utility survey standards in August 2017. In the beginning of 2018, Singapore-ETH Centre together with SLA and the Geomatics Department of the City of Zurich have embarked on the Digital Underground project to improve the understanding of the underground space through research, focusing on the development of a roadmap, a data model and best practices for a reliable 3D map of underground utilities.

A reliable 3D digital map of utility networks is crucial for urban planners to understand one of the most impactful aspects of the underground space. Additionally, a 3D map of utility networks could shed light on the management of utility networks such as their ownership and operation in order to ensure legal compliance, efficiency, and resilience of these utility networks. However, securing reliable data for a consolidated database with sufficient and consistently accurate information is a challenging task. A gap exists between engineering practices and mapping disciplines for underground utilities.

\subsection{Project objectives}

This work proposes to develop a 3D utility data model that aims to bridge the gap between underground utility surveying and data management. There are two main uses of this data model. One is for data sharing between government agencies, stakeholders, and other users. The other is to support cadastral management of underground utility networks. The following gaps and issues between underground utility survey to data management have been identified.

- The organisation of different roles for the sharing of data. It is necessary to clear governance of different roles. During data sharing, the communication between different roles (e.g. data producers, regulatory bodies and users) is very important.

- The administration of datasets for each type of role. Related to the ownership of datasets, different roles require different permissions to access data, especially maintenance.

- The integration of different types of datasets from different surveying methods. Non-destructive mapping technologies, such as Ground Penetrating Radar (GPR), Inertial Measurement Units (IMU) and gyroscope-based systems, are used to acquire data of new and existing utility networks as the input for the proposed data model after undergoing pre-processing steps. Integrating different types or formats of datasets in the data model is necessary. In addition, geometrical information (planimetric location) of the utility networks is retrieved from radargrams and converted to geospatial data with point, line or polygon features in a Geographical Information System (GIS) platform. The GPR data needs to be integrated with buried depth (Z).

- The conversion of datasets resulting from underground utility surveys to datasets required for a particular application. The data model needs to build the connection from data capture to data usage. It should provide reliable and comprehensive information to end users.

This paper first introduces related works on 3D underground utility data acquisition and reviews existing data models of utility networks. Section 3 proposes a framework to resolve the mentioned issues from information collection to the design of data model for underground utility networks, which includes a 3D utility network data model and a 3D utility cadastral data model. The last section presents conclusions and directions for future work.

\section{RELATED WORKS}

\subsection{The Technologies for 3D Underground Utility Data Ac- quisition}

Most of the underground utility mapping specialists are working with a workflow as described in figure 3 , where data acquisition, processing and management are undeniably interrelated. In short, underground utility mapping is performing from locating and testing to imaging and diagnosis after all data management (Lai et al., 2018b). 3D geospatial data acquired from the field containing as-built location and depth information of utility services are analysed and visualised as georeferenced utility network data in a GIS system (Jaw et al., 2018). However, under-

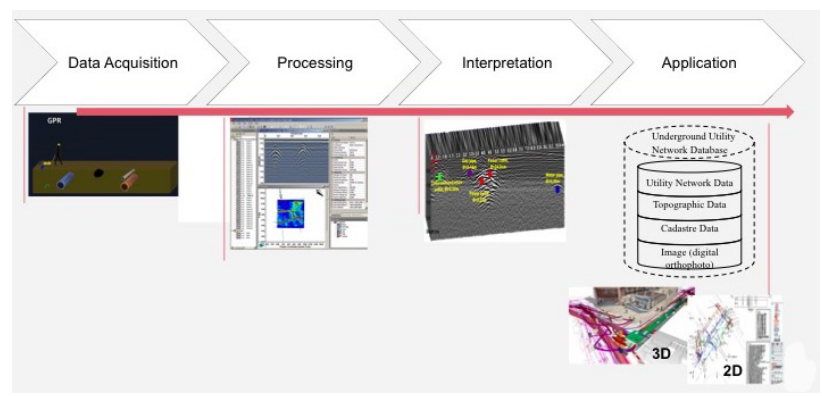

Figure 3 . Workflow of underground utility mapping.

ground utility mapping is different from typical above-ground engineering survey, as most utility networks are buried underground which is invisible to the surveyors eyes. As such, underground utility mapping only can be done using non-destructive geophysical mapping technologies that operate in electromagnetic, acoustic, magnetic, resistivity and gyro-based manners. Among these mapping technologies, ground penetrating radar (GPR) and orientation measurement units (OMU) are the most accepted nondestructive 3D mapping technologies for acquiring 3D reliable as-built information of the buried utility networks. Both of these 
technologies are selected as the primary data acquisition instruments for this Digital Underground project.

GPR is widely used in underground utility mapping, particularly in locating and testing towards a diagnosis for determining the geometrical information of the buried utility networks (Lai et al., 2018a). The GPR antenna transmits electromagnetic signals into the ground and records the signals that are reflected on the ground surface when it encounters inhomogeneity. It records the contradictions of electrical discontinuity between the medium and the inhomogeneity of the buried objects. However, it is noticeably complicated to convert GPR data to reliable 3D information of underground utilities (Figure 4) and the surrounding soil profile may limit the operation of the GPR system.

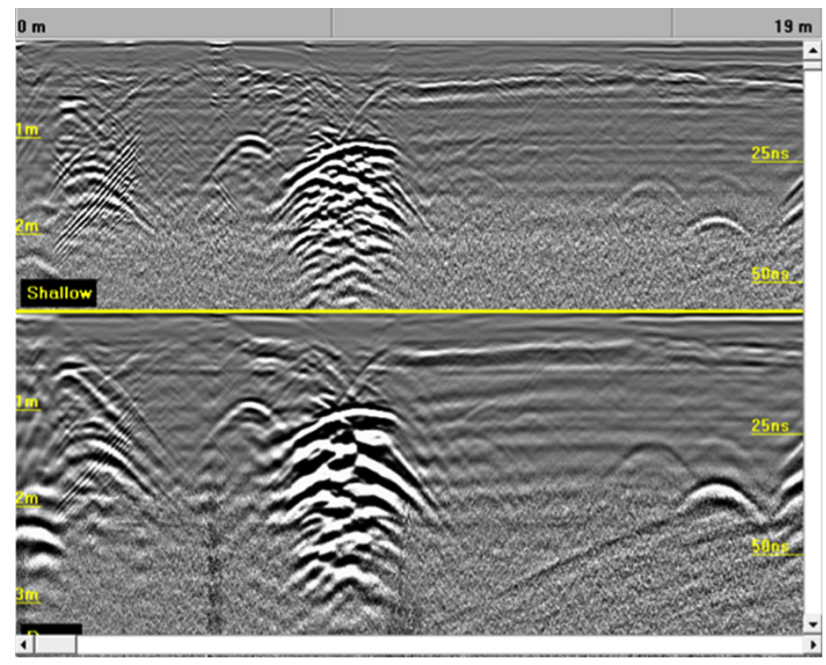

Figure 4. An example of GPR data.

Gyroscopic pipeline mapping systems are a relatively new technology that can be used to measure the profile of a pipe segment in 3D (x,y and $\mathrm{z}$ ). Using an orientation measurement unit (OMU), it can be used to acquire the as-built information of the utility network that is buried deeply and is difficult to sense using GPR. The benefit of using this type of mapping system is that it is irrelevant to know the exact position of the measurement unit as it travels from entry to exit point (REDUCT, 2017). It operates autonomously (no tethering of data cable) and can be used at any depth. Figure 5 shows an example of the output of a gyroscopic mapping unit.

\begin{tabular}{|c|c|c|c|c|c|c|}
\hline $\begin{array}{c}\text { Distance } \\
\text { from WPA }\end{array}$ & $\begin{array}{c}\text { coordinate } \\
\text { Easting }\end{array}$ & $\begin{array}{c}\text { coordinate } \\
\text { Northing }\end{array}$ & \multicolumn{1}{c}{$\begin{array}{c}\text { coordinate } \\
\text { Depth }\end{array}$} & \multicolumn{2}{c|}{ Azimuth } & \multicolumn{2}{c|}{$\begin{array}{c}\text { Pitch } \\
\text { Bend radius } \\
\text { XYZ 10 m }\end{array}$} \\
\hline 0 & 20100.257 & -82979.047 & 33.302 & 0 & 0 & 0 \\
\hline 1 & 20100.975 & -82979.654 & 32.947 & 130.2 & -20.7 & 0 \\
\hline 2 & 20101.688 & -82980.255 & 32.59 & 130.1 & -21 & 0 \\
\hline 3 & 20102.404 & -82980.857 & 32.234 & 130.1 & -20.8 & 0 \\
\hline 4 & 20103.121 & -82981.453 & 31.868 & 129.7 & -21.4 & 0 \\
\hline 5 & 20103.837 & -82982.044 & 31.503 & 129.6 & -21.4 & 199 \\
\hline 6 & 20104.552 & -82982.635 & 31.14 & 129.6 & -21.4 & 115 \\
\hline 7 & 20105.28 & -82983.236 & 30.775 & 129.5 & -21.2 & 64 \\
\hline 8 & 20106 & -82983.816 & 30.42 & 128.9 & -21 & 45 \\
\hline 9 & 20106.739 & -82984.391 & 30.066 & 127.9 & -20.7 & 37 \\
\hline 10 & 20107.464 & -82984.99 & 29.734 & 129.5 & -19.4 & 35
\end{tabular}

Figure 5. An example of gyroscopic mapping output.

It can be concluded that each technology has its advantages and limitations. The selection of using the right instrument depends on its application. A comprehensive collection of utility network mapping technologies may be required to acquire reliable 3D utility network data. The data that is obtained by different instruments needs to be integrated with utility networks attributes before storing in a geospatial database to support 3D visualisation, utility data management, urban planning and others application.

\subsection{The lack of 3D Data Model for Underground Utility Net- works}

A range of utility data models has been developed for storage, visualisation, exchange, analysis in the geospatial domain. For example, the CityGML utility network ADE (Becker et al., 2011) integrates utility infrastructure into the urban space, the Industry Foundation Classes (IFC) utility model (Liebich, 2009) represents utility services in a building, the ArcGIS utility model (ESRI, 2017) provides a GIS-based utility solution to represent the underlying logical and physical relations of utility networks, and the INSPIRE utility networks model (JRC, 2013) defines the basic application schema of utility networks in a city or country range. However, most of them focus on 2D representation without 3D geometric information of utilities, with the exception of the CityGML utility network ADE and the IFC utility model.

The CityGML utility network ADE focuses mainly on the representation of topographical, graph structural and functional information across the multi-utility networks in 3D space (Becker et al., 2011, Becker et al., 2013). This data model not only represents a utility network component by its 3D topography and complementary graph structure (Becker et al., 2011), but also considers interdependencies between utility network features and city objects (Hijazi et al., 2017). However, it does not consider the surveying method used to capture the data. The IFC utility model, which is an ISO standard for data exchange, pays more attention to the supply service of buildings in the civil engineering and architecture domain. It describes $2 \mathrm{D}$ and 3D geometry of utilities within the building and the logical or physical connection between building service components. However, the IFC utility model lacks spatial information.

Currently, there is not a widely accepted international standard for an underground utility data model (Lieberman and Ryan, 2017). Even though the standardized data models, such as CityGML and IFC have been developed to integrate multi-layer utility network data, these data models do not guarantee the information to be reliable, and there is currently no integration with above-ground urban features. Moreover, industry service providers are often not aware of these extensive standards that should ideally guide mapping procedures and accuracy requirements for underground utility network mapping. In order to provide utility data for 3D visualisation and other applications, it is necessary to integrate different types of utility datasets from multiple surveying methods. In addition, few existing works (Hashim et al., 2010, Pouliot et al., 2015) consider the cadastre application for underground infrastructures. The surveying method is related to data accuracy and data management directly. Hence, we need a 3D utility data model to fill the gap between underground survey and land administration applications.

\section{DESIGN OF A 3D DATA MODEL FOR UNDERGROUND UTILITY NETWORKS}

\subsection{A Framework for 3D Utility Network Mapping}

This work proposes a framework to organise the workflow from data capture to data usage at a top level (Figure 6), which aims 
to resolve issues about communication between different organisations, data integration, and data sharing during 3D mapping of underground utility networsk. This framework organises information in three parts: a utility survey, utility network data management, and utility cadastral management. This framework consists of four roles and two types of utility data models related to 3D underground utility network mapping. The four roles listed are the following:

- A data producer, who can be a contractor and/or part of the data regulatory bodies' organisation, will submit data to the utility network database after utility survey.

- Data regulatory bodies, which are government agencies, will collect data and manage them based on their utility network data model. The data regulatory bodies should provide a clear data permission and predefined subset of utility data, which will be used by data integrator.

- The data integrator integrates all utility data and manages the utility cadastre of all the utility networks in a city or country. The data integrator should provide the required information for the application of utility cadastre management to users. This role plays a vital role in this framework, connecting the data regulatory bodies and users.

- Data users can use utility data for utility cadastre management applications.

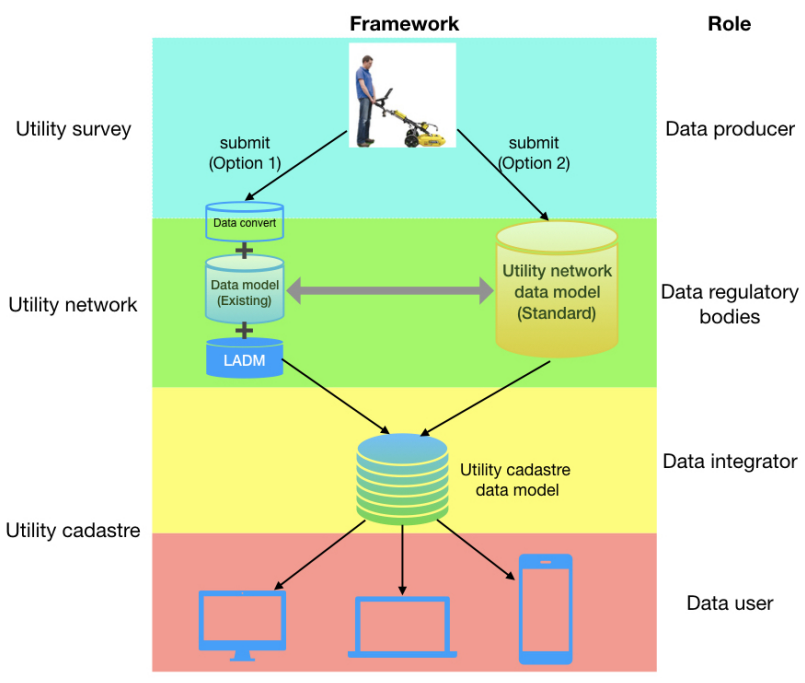

Figure 6. The framework of 3D underground utility network data modelling.

A survey, which includes an interview and questionnaire, will be developed to understand the requirements of different roles in different stages. In this work, the targets of the survey should be all involved Singapore government agencies, such as the Singapore Land Authority, Public Utilities Board, Jurong Town Corporation and so on. Related to different roles in different parts of the framework, the questionnaire is designed in five groups, four of which relate to the four user roles and one group of general questions for all the participants. According to the results of the survey, three main sets of information should be clearly defined at the framework level: i) the standard of communication between different roles from data capture to data using; ii) the definition of different roles including their usage and operation of a utility data model; iii) the permissions to access and modify utility data for each stage.

\subsection{D Utility Data Model}

A challenge related to ownership of utility data is how to combine existing utility data with the new utility network data model. As some data regulatory bodies do not want to share all of their existing utility network data and some of them have not developed their own utility network databases, this framework provides two options for collecting surveyed utility data. One is based on the existing utility network data model from data regulatory bodies. However, for newly surveyed utility data and bringing it into the utility cadastre, the data regulatory body needs to extend their existing utility data model to include two more components: data conversion and a Land Administration Data Model (LADM).

- The data conversion component establishes a connection between the utility survey and a utility network database. On one hand, the data conversion component will provide information to help data producers for their field work. On the other hand, utility survey data should be converted to 3D geospatial information during the data submission.

- The LADM component plays a key role in connecting the utility network database to develop the utility cadastre data model. There are two main objectives of the cadastre component. One is to identify what level of utility data can be accessed by data integrators and users in the utility cadastral management. The other is to integrate the utility network data model with the LADM (International Standards Organization, 2012).

In addition, a new utility network data model will be developed as a standard for the data integrator. Because some data regulatory bodies do not have their own utility network database or their existing data model cannot be extended, this is the second option for them to collect surveyed data and manage the utility network database. To do so, standards and specifications for utility network mapping for Singapore and other countries were reviewed. From these studies, it is concluded that two kinds of information about the utility network are required, being (i) type and topological information, i.e. a pipelines function, connected networks, etc. and (ii) attributes and geometry, i.e. pipe location, diameter, material, etc. These are then specified and used to develop the proposed 3D utility network data model.

Based on the LADM component of 3D utility network data model, the 3D utility cadastral data model aims to register utility objects and manage the ownership of underground utility. This part aims to support the registration and 3D cadastral mapping of underground utility networks. Up to now, there isnt a regulation or standard for a utility cadastre in Singapore. Before the development of utility cadastral data model, it is necessary to clarify the purpose and required level of quality of that data model. Based on the analysis of end-users requirement, the utility cadastral serve may not only support utility owners to maintain and manage the utility networks, but also support other user applications, such as urban planning and utility network simulations.

\section{CONCLUSIONS}

The proposed framework serves as a backbone for 3D underground utility mapping. This framework acts like a standard to 
organise the workflow of utility data survey, management and application. This framework is made up of four roles and two kinds of the data model. According to interviews and questionnaires, this work needs to clearly define different roles, including their operations and rights for 3D underground utility mapping. The utility network data model is capable of integrating utility networks data of varying formats, which were acquired using a variety of non-destructive surveying technologies. This data model is a first step towards bridging the gap between data acquisition and data management for underground utility mapping. At the same time, a crucial part of the utility network data model is to connect the utility network data model with the utility cadastral data model. To fully support underground space planning, the cadastral data model should eventually be extended to include other underground features in the future, such as underground substations, pedestrian links, common services tunnels, road and rail networks, etc. Also, to support ownership management applications, it should be integrated with the existing Land Administration Domain Model for 3D cadastral management of underground space in Singapore. Such a reliable and complete centralised repository of underground utility data will provide a crucial basis for planning and administering underground spaces.

This work is a work in progress and is in its initial stages. The next step will be the development of a utility network data model and a utility cadastral data model. In the second stage, a pilot study will be conducted to implement the entire process from data capture to data integration and application, working with a selection of agencies and the preferred data integrator. It aims to evaluate and improve the framework. After that, recommendations from this study can be used for the implementation of the platform in Singapore with all government agencies. Also, this work will not limit itself to underground utilities. In future work, it will be extended to include other underground structures such as underground indoor spaces, and support urban planning applications.

\section{ACKNOWLEDGEMENTS}

This publication has been realized as part of the Digital Underground: 3D Mapping of Utility Networks project at the Future Cities Laboratory, established by ETH-Zurich and Singapores National Research Foundation (NRF), and operates under the auspices of the Singapore-ETH Centre. The project is funded by the UNDERGROUND-RELATED STUDIES AND PROJECTS FUND (USPF), Ministry of National Development and is sponsored by Singapore Land Authority.

The authors would also like to thank the Geomatics Department of the City of Zurich for sharing their previous experiences and insights on data model development.

\section{REFERENCES}

Becker, T., Nagel, C. and Kolbe, T. H., 2011. Integrated 3d modeling of multi-utility networks and their interdependencies for critical infrastructure analysis. In: Advances in $3 D$ GeoInformation Sciences, Springer, pp. 1-20.

Becker, T., Nagel, C. and Kolbe, T. H., 2013. Semantic 3d modeling of multi-utility networks in cities for analysis and $3 \mathrm{~d}$ visualization. In: Progress and New Trends in 3D Geoinformation Sciences, Springer, pp. 41-62.
ESRI, 2017. What are geometric networks? https://desktop.arcgis.com/en/arcmap/10.3/manage-

data/geometric-networks/what-are-geometric-networks-.htm.

Hashim, M., Wei, J. S. and Marghany, M., 2010. Subsurface utility mapping for underground cadastral infrastructure. In: $31 s t$ Asian Conference on Remote Sensing (ACRS 2010), pp. 1-5.

Hijazi, I., Kutzner, T. and Kolbe, T. H., 2017. Use Cases and their Requirements on the Semantic Modeling of 3d Supply and Disposal Networks. In: Kulturelles Erbe erfassen und bewahren-Von der Dokumentation zum virtuellen Rundgang, 37. Wissenschaftlich-Technische Jahrestagung der DGPF, pp. 288 301.

International Standards Organization, 2012. ISO 19152: Geographic information Land Administration Domain Model (LADM).

Jaw, S. W., Van Son, R., Khoo, V. H. S., Schrotter, G., Loo, R. W. K., Teo, S. S. N. and Yan, J., 2018. The Need for a Reliable Map of Utility Networks for Planning Underground Spaces. Rapperswil, Switzerland.

JRC, 2013. D2.8.III.6 INSPIRE Data Specification on Utility and Government Services Technical Guidelines. European Commission Joint Research Centre.

Lai, W. W. L., Chang, R. K. W. and Sham, J. F. C., 2018a. A blind test of nondestructive underground void detection by ground penetrating radar (GPR). Journal of Applied Geophysics 149, pp. 1017.

Lai, W. W.-L., Drobert, X. and Annan, P., 2018b. A review of ground penetrating radar application in civil engineering: a 30year journey from locating and testing to imaging and diagnosis. NDT \& E International 96, pp. 58-78.

Lieberman, J. and Ryan, A., 2017. OGC Underground Infrastructure Concept Study Engineering Report. OGC Engineering Report, Open Geospatial Consortium.

Liebich, T., 2009. IFC 2x Edition 3. In: Model implementation guide. version 2.0, AEC3 Ltd.

Pouliot, J. and Girard, P., 2016. 3d Cadastre: With or Without Subsurface Utility Network? International Federation of Surveyors (FIG), Athens, Greece. OCLC: 831214525.

Pouliot, J., Bordin, P. and Cuissard, R., 2015. Cadastral mapping for underground networks: A preliminary analysis of user needs. In: International Cartographic Conference, Brazil, pp. 08-23.

REDUCT, 2017. DuctRunner Technology Technical Method Statement. Technical report.

Tan, L. C. and Looi, K. S., 2013. Towards a Malaysian multipurpose $3 \mathrm{~d}$ cadastre based on the Land Administration Domain Model (LADM)an empirical study. In: Proceedings of the 5th FIG Land Administration Domain Model Workshop, pp. 24-25. 